\title{
High pretreatment serum gamma-glutamyl transpeptidase predicts an inferior outcome in nasopharyngeal carcinoma
}

\author{
Min Luo ${ }^{1}$, Wei Sun ${ }^{1}$, Cheng Wu ${ }^{1}$, Linli Zhang ${ }^{1}$, Dongbo Liu ${ }^{1}$, Wenwen Li ${ }^{1}$, Qi Mei ${ }^{1}$ \\ and Guoqing $\mathrm{Hu}^{1}$ \\ ${ }^{1}$ Department of Oncology, Tongji Hospital, Tongji Medical College, Huazhong University of Science and Technology, Hubei, \\ Wuhan, People's Republic of China \\ Correspondence to: Qi Mei, email: borisma@hotmail.com \\ Guoqing Hu, email: gqhu@tjh.tjmu.edu.cn
}

Keywords: nasopharyngeal carcinoma, serum marker, gamma-glutamyl transpeptidase, survival, prognosis

Received: September 20,2016 Accepted: June 02, $2017 \quad$ Published: June 28, 2017

Copyright: Luo et al. This is an open-access article distributed under the terms of the Creative Commons Attribution License 3.0 (CC BY 3.0), which permits unrestricted use, distribution, and reproduction in any medium, provided the original author and source are credited.

\section{ABSTRACT}

Background: Gamma-glutamyl transpeptidase (GGT) which plays an important role in tumor initiation, invasion, drug resistance is strongly associated with poor prognosis in patients with cancers. This study was designed to estimate whether pretreatment serum GGT could predict the clinical outcome of nasopharyngeal carcinoma (NPC) patients.

Results: An optimal cutoff value was identified as 23 U/L for GGT. Univariate analysis and multivariate analysis demonstrated that elevated GGT was correlated with shorter local recurrence-free survival (LRFS) (HR, 4.163; 95\% CI, 1.690-10.251; $p=0.023)$, progression-free survival (PFS) $(H R, 3.119 ; 95 \% C I, 1.955-4.976 ; p=0.031)$ and overall survival (OS) (HR, 2.811; 95\% CI, 1.614-4.896; p=0.007).

Materials and Methods: We retrospectively analyzed data from 374 patients with NPC. Kaplan-Meier method was used to calculate and compare the prognosis. The Cox proportional hazards model was applied to carry out univariate and multivariate analyses.

Conclusion: Pretreatment GGT can be a novel and independent prognostic biomarker for patients with NPC.

\section{INTRODUCTION}

Nasopharyngeal carcinoma (NPC) is one of the most common head and neck cancers in Southeast Asia, especially in Southern China. With the rapid development of radiotherapy technology and chemotherapy regimens, the 5-year survival rate of NPC has reached approximately $80 \%$ [1, 2]. However, locoregional recurrence and distant metastasis after treatment still remain the main failure patterns affecting the survival rate of patients with advanced NPC [3]. Thus, searching for biomarkers associated with the prognosis of NPC patients are urgently needed [4]. In recent years, plenty of evidences had shown that some molecular makers, such as lactate dehydrogenase (LDH) [5], neutrophil-lymphocyte ratio, platelet-lymphocyte ratio [6], Epstein-Barr virus [7] and c-reactive protein [8] could successfully stratify patients regarding to their prognosis. Tumor-nodes-metastasis (TNM) classification is currently the gold standard for risky group classification. However, patients even with the same TNM stages could have dramatically different survival results [7]. These inexpensive, objective and easily detected markers are of great value to complement the TNM staging system. 
Gamma-glutamyl transpeptidase (GGT) is a membrane-bound enzyme which can modulate the metabolism of glutathione (GSH) [9]. Located on the outer aspect of the cell membrane, GGT catalyzes the degradation of extracellular GSH and cleaves extracellular glutathione. By this way, GGT can provide the cells with access to additional cysteine and contribute to cellular antioxidant/antitoxic defenses [10]. Meanwhile, GGT may play a role in tumor initiation, invasion and drug resistance which could also predict poor prognosis of patients with cancers [11-13]. GGT included in routine biochemical examination was also showed as a promising prognostic factor for various cancers [14-20]. As a result, we supposed that GGT, a serum enzyme which can be acquired easily, may be of great value to predict prognosis in patients with NPC and guide individual treatment.

However, little is known about the association of pretreatment GGT and prognosis in patients with NPC. Therefore, we performed the present study to evaluate the association between pretreatment GGT and clinical outcome in patients with NPC.

\section{RESULTS}

\section{Patient characteristics}

In the end of follow-up, 374 patients were included and 145 patients were excluded. More details about how to select the patients into the study team were shown in Supplementary Table 1. The median age of diagnosis was 46 years. 263 were male and 111 were female, with a sex ratio of 2.4:1. There were 92 and 282 patients with stage I+II and III +IV disease, respectively. Chemotherapy was administered to 370 patients, while the other four was given radiotherapy alone. Concurrent chemoradiotherapy (CCT) was delivered to 66 patients, neoadjuvant chemotherapy (NACT) + CCT to 228 patients, CCT + adjuvant chemotherapy (ACT) to 6 patients, NACT + CCT + ACT to 74 patients. During follow-up, 92 patients $(24.6 \%)$ experienced tumor progression after treatment. By the end of follow-up, $65 / 374$ patients $(17.4 \%)$ had died. The 5-year local recurrence-free survival (LRFS), distant metastasis-free survival (DMFS), progression-free survival (PFS) and overall survival (OS) rates were 92.2\%, 83.5\%, 75.4\% and $82.6 \%$, respectively.

\section{ROC analysis}

Best cutoff value was determined by Receiveroperating characteristic (ROC) curve generated from MedCalc, with the highest combined sensitivity and specificity respecting to 5-year LRFS, 5-year DMFS, 5-year PFS and 5-year OS. Using 5-year LRFS as an end point, the cut-off value provided by ROC analysis was
23U/L for GGT. As showed in Figure 1A, area under the curve (AUC) of GGT is 0.774 ( $\mathrm{p}=0.0021$ ). Therefore, GGT could be identified as a potential prognostic biomarker in LRFS analysis. However, positive result was not acquired for DMFS, its AUC was 0.554 and $\mathrm{p}$ value was 0.0693 . The ROC curve for DMFS was presented in Figure 1B. GGT could be used as a prognostic biomarker for PFS and OS analysis with an optimal AUC (0.755, 0.620, respectively) and $\mathrm{p}$ value $(0.0001,0.0028$, respectively), which was presented in Figure 1C and Figure 1D. These values calculated by ROC analysis were adopted in subsequent survival analysis and used to stratify patients into different groups.

\section{Association between elevated GGT ( $\geq 23$ U/L) and clinical characteristics of patients with NPC}

Of the 374 patients, Elevated pretreatment GGT defined as $\geq 23 \mathrm{U} / \mathrm{L}$ based on our scan of cut-off values described above was detected in 185 NPC patients $(49.5 \%)$. Patients classified as male $(p<0.001), N 2+3$ $(p=0.013)$ and higher TNM stage $(p=0.031)$ were more likely to have elevated GGT (Table 1). In contrast, the frequency of elevated GGT was similar between the following subgroups of patients: those classified as WHO Type 2 and WHO Type $3(\mathrm{p}=0.758), \mathrm{T} 1+2$ and $\mathrm{T} 3+4$ $(\mathrm{p}=0.605)$.

\section{Univariate and multivariate analysis}

Univariate analyses were performed using gender, age, tumor classification, lymph node classification, TNM stage, histology and GGT as possible variables. N-stage $(p=0.044)$, TNM stage $(p=0.023)$ and GGT $(p=0.001$ Figure $2 A)$ were found to have relationships with inferior LRFS. Multivariate analysis confirmed that N-stage (HR, 2.549; 95\% CI, 1.545-4.771; $\mathrm{p}=0.047)$, TNM stage $(\mathrm{HR}, 4.599 ; 95 \% \mathrm{CI}, 1.087-$ $19.447 ; \mathrm{p}=0.038)$ and GGT (HR, 4.162; 95\% CI, $1.690-$ $10.25 ; \mathrm{p}=0.02)$ were independent risk factors for LRFS. Results were showed in Table 2. Univariate survival analysis also revealed an association between worse PFS and advanced T-stage $(\mathrm{p}<0.001)$, advanced N-stage $(\mathrm{p}<0.001)$, later TNM stage $(\mathrm{p}<0.001)$ and $\mathrm{GGT} \geq 23 \mathrm{U} / \mathrm{L}$ $(\mathrm{p}<0.001$, Figure 2B). Multivariate analysis ensured that advanced T-stage (HR, 1.847; 95\% CI, 1.106-3.084; $\mathrm{p}=0.019)$, advanced N-stage (HR, 1.827; 95\% CI,1.1262.966; $\mathrm{p}=0.015)$, later TNM stage (HR, 4.757; 95\% CI, 1.316-17.201; $\mathrm{p}=0.017)$ and $\mathrm{GGT} \geq 23 \mathrm{U} / \mathrm{L}(\mathrm{HR}, 3.119$; $95 \%$ CI, 1 wctors for PFS (Table 3 ). As showed in Table 4 , advanced T-stage $(\mathrm{p}<0.001)$, advanced $\mathrm{N}$-stage $(\mathrm{p}<0.001)$, later TNM stage $(\mathrm{p}<0.001)$, and GGT $\geq 23 \mathrm{U} / \mathrm{L}$ $(p<0.001$, Figure 2C) were statistically significantly associated with poorer OS. Other characteristics did not show a significant correlation with prognosis. Multivariate analysis was performed according to 
the meaningful variables above. Moreover, advanced T-stage (HR, 1.967; 95\% CI, 1.070-3.588; $\mathrm{p}=0.027$ ), later TNM stage (HR, 4.231; 95\% CI, 0.833-20.270; $\mathrm{p}=0.01)$ and GGT $\geq 23 \mathrm{U} / \mathrm{L}$ (HR, 2.811; 95\% CI, 1.614$4.896 ; \mathrm{p}=0.007)$ were independent prognostic factors for OS.

\section{Subgroup analysis stratified by clinical stages}

Patients with different clinical stages were included in our study. This would cause bias, for example, the TNM stage was not balanceable in GGT groups, and the treatments were different between patients with early stage and patients with advanced stage. Thus, we further performed a subgroup analysis and evaluated the prognostic roles of GGT in NPC patients with different clinical stages. No statistical significances were observed in the early-stage subgroup $(\mathrm{p}=0.752$ for LRFS; $\mathrm{p}=0.331$ for DMFS; $p=0.731$ for OS; Figure $3 \mathrm{~A}-3 \mathrm{C}$ ). However, positive results were obtained in the advanced subgroup ( $p=0.001$ for LRFS; $p<0.001$ for DMFS; $p<0.001$ for OS; Figure 3D-3F).
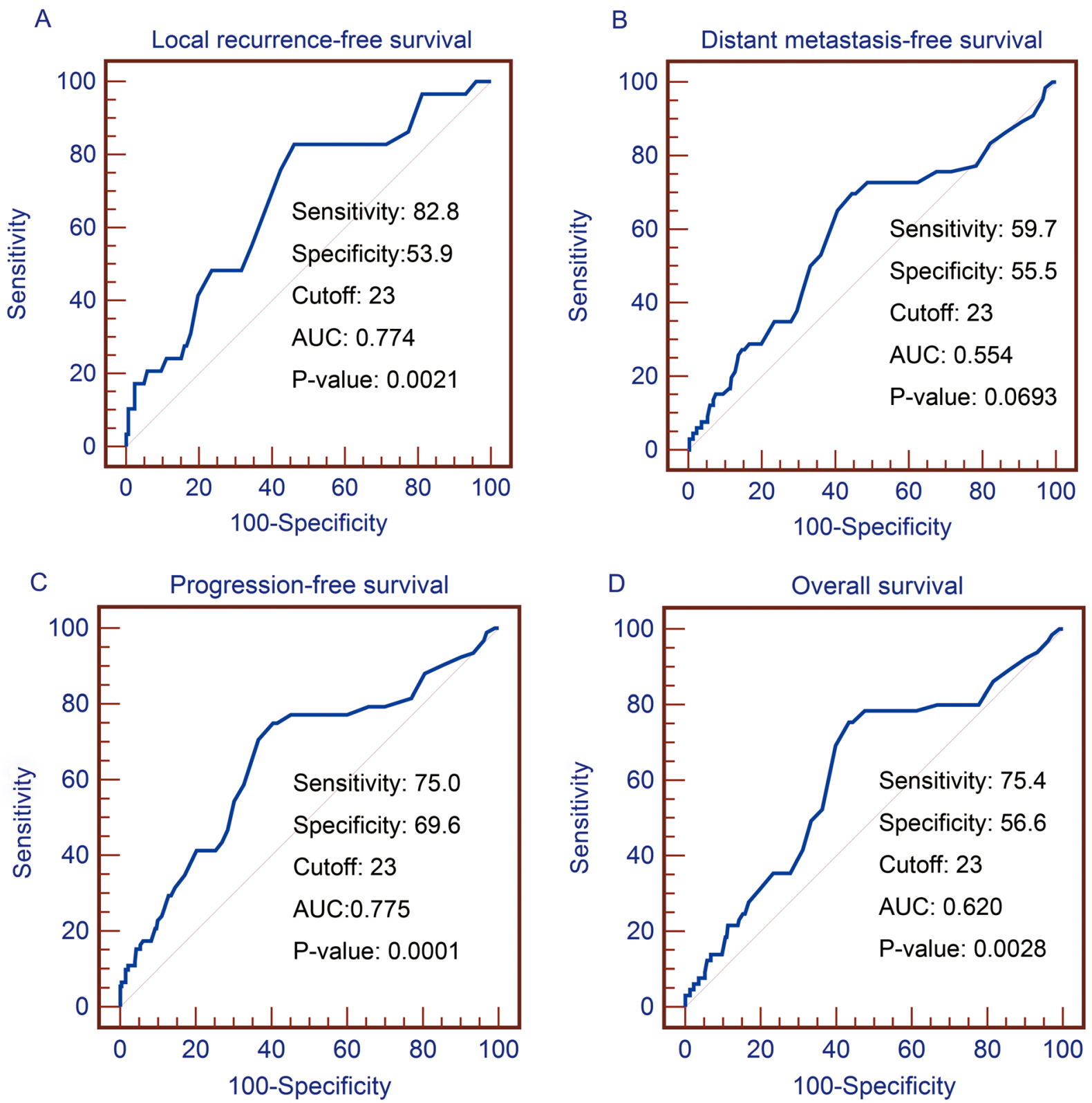

Figure 1. ROC analyses for the pretreatment serum GGT level. (A) Using LRFS as an end point, the cut-off values provided by ROC analysis were 23 for GGT. Using DMFS (B), PFS (C) and OS (D) as an end point, the cut-off values were the same.

ROC, receiver-operating characteristic; GGT, gamma-glutamyl transpeptidase; LRFS, local relapse-free survival; DMFS, distant metastasisfree survival; PFS, progression-free survival; OS, overall survival. 
Table 1: Associations of serum level of GGT and clinical-pathological characteristics in NPC

\begin{tabular}{|c|c|c|c|}
\hline \multirow{2}{*}{ Parameter } & \multicolumn{2}{|c|}{ Pretreatment serum GGT level n(c\%) } & \multirow{2}{*}{ P-value } \\
\hline & $<23 \mathrm{U} / \mathrm{L}$ & $\geq 23 \mathrm{U} / \mathrm{L}$ & \\
\hline \multicolumn{4}{|l|}{ Gender } \\
\hline Female & $79(41.8)$ & $32(17.3)$ & \\
\hline Male & $110(58.2)$ & $153(82.7)$ & $<0.001$ \\
\hline \multicolumn{4}{|l|}{ Histology } \\
\hline WHO Type 2 & $94(51.4)$ & $95(49.7)$ & \\
\hline WHO Type 3 & $89(48.6)$ & $96(50.3)$ & 0.758 \\
\hline \multicolumn{4}{|c|}{ Age at diagnosis (years) } \\
\hline$<50$ & $133(51.2)$ & $60(52.6)$ & \\
\hline$\geq 50$ & $127(48.8)$ & $54(47.4)$ & 0.473 \\
\hline \multicolumn{4}{|c|}{ Tumor classification } \\
\hline $\mathrm{T} 1+2$ & $98(51.9)$ & $90(48.6)$ & \\
\hline $\mathrm{T} 3+4$ & $91(48.1)$ & $95(51.4)$ & 0.605 \\
\hline \multicolumn{4}{|c|}{ Lymph node classification } \\
\hline $\mathrm{N} 0+1$ & $102(54.0)$ & $76(41.1)$ & \\
\hline $\mathrm{N} 2+3$ & $87(46.0)$ & $109(58.9)$ & 0.013 \\
\hline \multicolumn{4}{|c|}{ TNM stage(AJCC) } \\
\hline $\mathrm{I}+\mathrm{II}$ & $55(29.1)$ & $36(19.5)$ & \\
\hline III+IV & $134(70.9)$ & $149(80.5)$ & 0.031 \\
\hline
\end{tabular}

GGT, gamma-glutamyl transpeptidase; WHO, World Health Organization histological classification; TNM, tumor nodes metastasis-classification; AJCC, American Joint Committee on Cancer.

\section{Subgroup analysis stratified by different genders}

As shown in previous study, the normal reference range of GGT was not same [21]. In order to avoid the bias, we further performed a subgroup analysis and evaluated the prognostic roles of GGT in NPC patients with different clinical genders. GGT was identified as a positive predictor simultaneously among male and female in Figure 4.

\section{DISCUSSION}

In recent years, improvements in diagnostic methods, radiotherapy techniques, chemotherapy regimens and novel therapies have offered vital survival benefits in locally advanced NPC [22-24]. However, more than $20 \%$ advanced NPC patients developed distant metastasis after treatment, making accurate prognostic evaluation at diagnosis extremely important for maximizing therapy benefits $[25,26]$. Patients even with the same TNM stages could have dramatically different survival results [7]. Therefore, various molecular biomarkers have been studied to satisfy the demand of a more accurate prognostic system [5, 6, 27-29].

Abberant expression of GGT was found in several human tumors, including renal cell carcinoma [14], esophageal squamous cell carcinoma [15], colorectal cancer [17], and breast cancer [18], cervical cancer [19] and ovarian cancer [20]. A tight relationship was documented by many large multicenter trials between higher GGT and cancer incidence or mortality [30-33]. Cells which overexpressed GGT were shown to be more resistant to chemotherapies such as doxorubicin [34], cisplatin [11, 35, 36] and 5-fluorouracil [37] than normal 
cancer cells. Patients with stage IIb to IV disease then had to receive concurrent chemoradiotherapy and/or neoadjuvant or adjuvant chemotherapy with cisplatin or 5-fluorouracil [23]. Therefore, we would ascribe the weak results to the influence of GGT on medications. These studies revealed a promising prospect of GGT on the prediction of cancer and complement TNM classification. However, there were few studies focused on the relevance between GGT and NPC. Only one study identified that high GGT was not a prognostic factor for NPC [38], but it just conducted the trial with GGT level above normal and did not determined a cutoff value. Moreover, the low percentage of patients with high GGT in that study couldn't meet the need of statistical analyses. In our study, we identified a meaningful cutoff value and found that high GGT had a significant relationship with poor prognosis of NPC patients.

In this study, GGT $\geq 23 \mathrm{U} / \mathrm{L}$ was identified as a potential biomaker for LRFS, PFS and OS. However, GGT couldn't be identified as a meaningful biomarker for DMFS because of its inferior AUC and $\mathrm{P}$ value. Subsequently, the associations of the GGT with the clinical-pathological features of NPC were investigated. Patients classified as male, higher $\mathrm{N}$-stage and advanced TNM stage were more likely to have elevated GGT. Healthy men different from women were inclined to
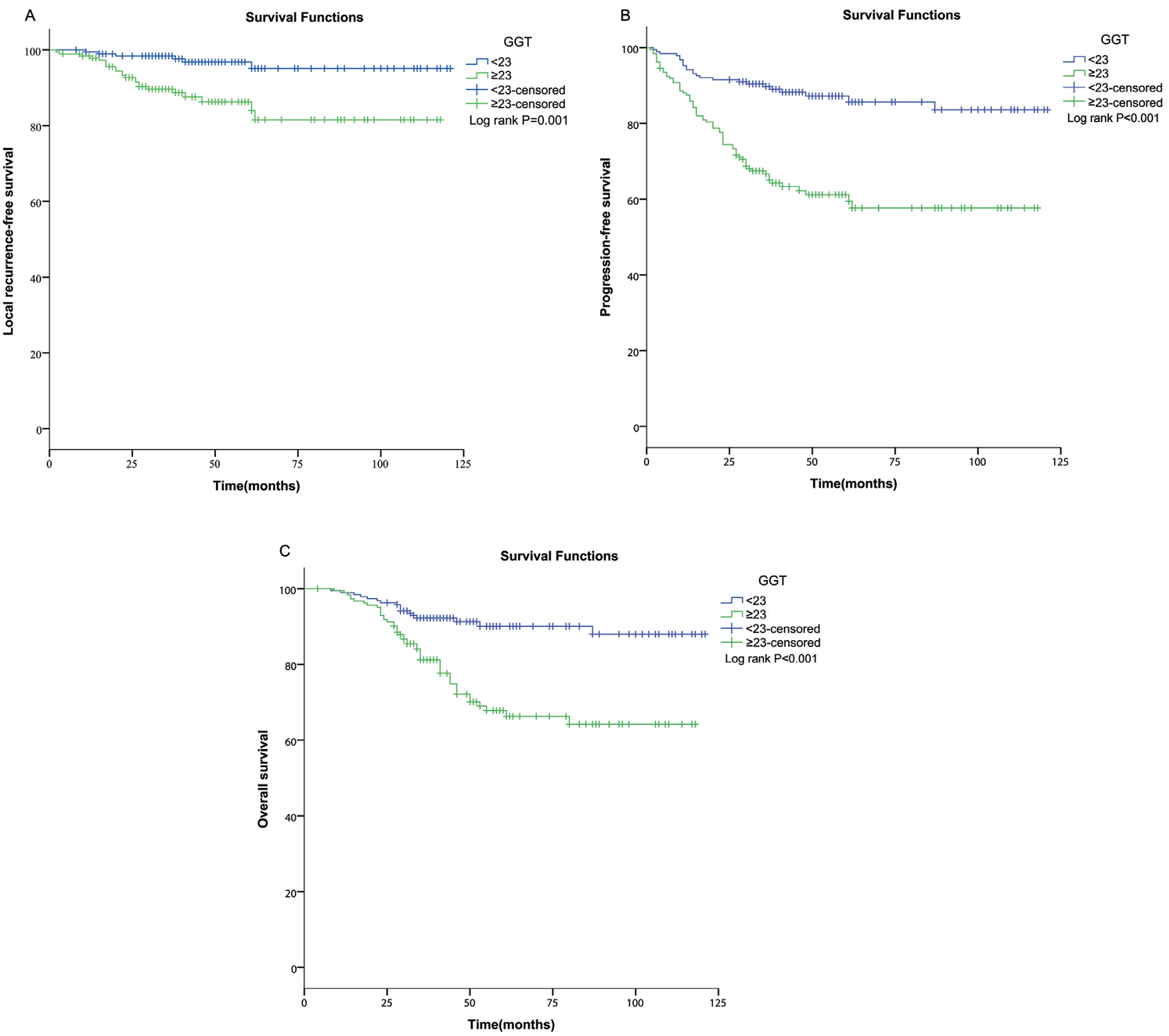

Figure 2. Kaplan-Meier analyses of LRFS, PFS and OS according to pretreatment serum GGT level. Compared to the low subset $(\mathrm{GGT}<23 \mathrm{U} / \mathrm{L})$, elevated serum GGT level $(\geq 23.0 \mathrm{U} / \mathrm{L})$ had an inferior (A) LRFS $(\mathrm{p}=0.001)$, (B) PFS ( $<<0.001)$ and $(\mathbf{C})$ OS $(\mathrm{p}<0.001)$.

ROC, receiver-operating characteristic; GGT, gamma-glutamyl transpeptidase; LRFS, local relapse-free survival; PFS, progression-free survival; OS, overall survival. 
Table 2: Univariate and multivariate analysis of clinicopathological parameters for the prediction of local recurrence-free survival in patients with nasopharyngeal carcinoma $(n=374)$

\begin{tabular}{|c|c|c|c|c|}
\hline \multirow[b]{2}{*}{ Parameter } & \multicolumn{2}{|c|}{ Univariate analysis } & \multicolumn{2}{|c|}{ Multivariate analysis } \\
\hline & HR(95\% CI) & P-value & HR (95\% CI) & P-value \\
\hline \multicolumn{5}{|l|}{ Gender } \\
\hline Female & 1(Referent) & & & \\
\hline Male & $2.338(0.888-6.151)$ & 0.085 & & \\
\hline \multicolumn{5}{|l|}{ Histology } \\
\hline WHO Type 2 & 1(Referent) & & & \\
\hline WHO Type 3 & $0.976(0.469-2.030)$ & 0.947 & & \\
\hline \multicolumn{5}{|c|}{$\begin{array}{l}\text { Age at diagnosis } \\
\text { (years) }\end{array}$} \\
\hline$<50$ & 1(Referent) & & & \\
\hline$\geq 50$ & $1.003(0.431-2.209)$ & 0.991 & & \\
\hline \multicolumn{5}{|c|}{ Tumor classification } \\
\hline $\mathrm{T} 1+2$ & 1(Referent) & & & \\
\hline $\mathrm{T} 3+4$ & $1.477(0.703-3.102)$ & 0.303 & & \\
\hline \multicolumn{5}{|l|}{$\begin{array}{l}\text { Lymph node } \\
\text { classification }\end{array}$} \\
\hline $\mathrm{N} 0+1$ & 1 (Referent) & & & \\
\hline $\mathrm{N} 2+3$ & $2.037(0.954-4.346)$ & 0.044 & $2.549(1.545-4.771)$ & 0.047 \\
\hline \multicolumn{5}{|c|}{ TNM stage(AJCC) } \\
\hline $\mathrm{I}+\mathrm{II}$ & 1(Referent) & & & \\
\hline III+IV & $5.341(1.266-22.540)$ & 0.023 & $4.399(1.089-19.447)$ & 0.038 \\
\hline \multicolumn{5}{|l|}{ GGT } \\
\hline$<23$ & 1(Referent) & & & \\
\hline$\geq 23$ & $4.559(1.854-11.215)$ & 0.001 & $4.163(1.690-10.251)$ & 0.020 \\
\hline
\end{tabular}

GGT, Gamma-glutamyl transpeptidase; WHO, World Health Organization histological classification; TNM, tumor nodes metastasis-classification; AJCC, American Joint Committee on Cancer; HR, hazard ratio; 95\% CI, 95\% confidence interval.

have higher upper reference interval of GGT [21], which might explain why elevated GGT was found in men. The results were consistent with the previous studies on the associations between GGT and clinical-pathological parameters [15]. In order to avoid the deflection between different genders, Kaplan-Meier analysis was performed. GGT was identified as a positive predictor simultaneously among male and female (Figure 4). Besides, GGT was elevated in the NPC patients with higher N-stage, and lymph node status was a strong predictor for NPC patients. The impact of GGT on prognosis might result from the association between GGT and lymph node status. Univariate survival analysis and multivariate analysis confirmed that GGT and lymph node status were positive prognostic factors for NPC patients. We also found a link between elevated GGT and advanced TNM stage which was different from other studies $[16,18]$. The difference might be due to tumor heterogeneity and different cut-off values. When univariate survival analysis and multivariate analysis were performed, we successfully identified that GGT was an independent prognostic factor for NPC patients. High pretreatment GGT level was correlated with poor 5-year LRFS (HR, 4.162; 95\% CI, 1.690-10.251; $\mathrm{P}=0.02)$, PFS (HR, 3.119; 95\% CI, 1.955-4.976; $\mathrm{P}=0.031$ ) and OS (HR, 2.811; 95\% CI, 1.614-4.896; $\mathrm{P}=0.007$ ).

In our subgroup analysis, significant associations of GGT with prognosis were observed among patients with advanced stage. For the early stage group, there were no 
Table 3: Univariate and multivariate analysis of clinicopathological parameters for the prediction of progressionfree survival in patients with nasopharyngeal carcinoma $(n=374)$

\begin{tabular}{|c|c|c|c|c|}
\hline \multirow[b]{2}{*}{ Parameter } & \multicolumn{2}{|c|}{ Univariate analysis } & \multicolumn{2}{|c|}{ Multivariate analysis } \\
\hline & HR(95\% CI) & P-value & HR (95\% CI) & P-value \\
\hline \multicolumn{5}{|l|}{ Gender } \\
\hline Female & 1(Referent) & & & \\
\hline Male & $3.272(1.781-6.01)$ & 0.091 & & \\
\hline \multicolumn{5}{|l|}{ Histology } \\
\hline WHO Type 2 & 1(Referent) & & & \\
\hline WHO Type 3 & $0.813(0.539-1.227)$ & 0.324 & & \\
\hline \multicolumn{5}{|c|}{$\begin{array}{l}\text { Age at diagnosis } \\
\text { (years) }\end{array}$} \\
\hline$<50$ & 1(Referent) & & & \\
\hline$\geq 50$ & $1.154(0.751-1.773)$ & 0.513 & & \\
\hline \multicolumn{5}{|c|}{ Tumor classification } \\
\hline $\mathrm{T} 1+2$ & 1(Referent) & & & \\
\hline $\mathrm{T} 3+4$ & $2.876(1.814-4.558)$ & $<0.001$ & $1.847(1.106-3.084)$ & 0.019 \\
\hline \multicolumn{5}{|l|}{$\begin{array}{l}\text { Lymph node } \\
\text { classification }\end{array}$} \\
\hline $\mathrm{N} 0+1$ & 1 (Referent) & & & \\
\hline $\mathrm{N} 2+3$ & $2.550(1.644-3.953)$ & $<0.001$ & $1.827(1.126-2.966)$ & 0.015 \\
\hline \multicolumn{5}{|c|}{ TNM stage(AJCC) } \\
\hline $\mathrm{I}+\mathrm{II}$ & 1(Referent) & & & \\
\hline III+IV & $11.791(3.728-37.225)$ & $<0.001$ & $4.757(1.316-17.201)$ & 0.017 \\
\hline \multicolumn{5}{|l|}{ GGT } \\
\hline$<23$ & 1(Referent) & & & \\
\hline$\geq 23$ & $3.465(2.174-5.523)$ & $<0.001$ & $3.119(1.955-4.976)$ & 0.031 \\
\hline
\end{tabular}

GGT, Gamma-glutamyl transpeptidase; WHO, World Health Organization histological classification; TNM, tumor nodes metastasis-classification; AJCC, American Joint Committee on Cancer; HR, hazard ratio; 95\% CI, 95\% confidence interval.

statistical significances between GGT and prognosis. Our results indicated that GGT seemed to be more effective for patients with advanced stage. Patients with NPC with early clinical stage tended to survive longer without progression. In our study, only 6 cases progressed and 2 patients died among the 92 patients with early-stage disease. The small number of outcome (progression or death) might attribute this nonsignificant association in the early stage. This subgroup analysis would make our study more intuitive and scientific.

GGT anchored in the cell membrane is a cell surface glycoprotein which can regulate the glutathione (GSH) metabolism. Protein synthesis is starving of the recovery of cysteine mediated by GGT especially in rapidly dividing neoplastic cells [39]. Meanwhile, GGT have been documented by large amount of studies to modulate the crucial redox related courses [40,41], such as antioxidant/ antitoxic defenses and cellular proliferative/apoptotic balance. The pro-oxidant reactions produced by GGT could supplement endogenous Reactive oxygen species (ROS) in cancer cells, and endogenous ROS can contribute to the 'persistent oxidative stress', which is described as a factor in genomic instability and carcinogenesis [42]. Furthermore, a great number of cytokines including tumor necrosis factor alpha (TNF-alpha) [43], and interferon (IFN)-alpha and -beta [44], could induce GGT mRNA expression. These results indicate a connection between inflammation and GGT expression, not just as a response 
Table 4: Univariate and multivariate analysis of clinicopathological parameters for the prediction of overall survival in patients with nasopharyngeal carcinoma $(n=374)$

\begin{tabular}{|c|c|c|c|c|}
\hline \multirow{2}{*}{ Parameter } & \multicolumn{2}{|c|}{ Univariate analysis } & \multicolumn{2}{|c|}{ Multivariate analysis } \\
\hline & HR(95\% CI) & P-value & HR $(95 \%$ CI $)$ & P-value \\
\hline \multicolumn{5}{|l|}{ Gender } \\
\hline Female & 1(Referent) & & & \\
\hline Male & $2.615(1.332-5.134)$ & 0.073 & & \\
\hline \multicolumn{5}{|l|}{ Histology } \\
\hline WHO Type 2 & 1(Referent) & & & \\
\hline WHO Type 3 & $0.787(0.482-1.960)$ & 0.338 & & \\
\hline \multicolumn{5}{|c|}{$\begin{array}{l}\text { Age at diagnosis } \\
\text { (years) }\end{array}$} \\
\hline$<50$ & 1(Referent) & & & \\
\hline$\geq 50$ & $1.172(0.701-1.960)$ & 0.545 & & \\
\hline \multicolumn{5}{|c|}{ Tumor classification } \\
\hline $\mathrm{T} 1+2$ & 1(Referent) & & & \\
\hline $\mathrm{T} 3+4$ & $2.289(1.640-4.880)$ & $<0.001$ & $1.967(1.070-3.588)$ & 0.027 \\
\hline \multicolumn{5}{|l|}{$\begin{array}{l}\text { Lymph node } \\
\text { classification }\end{array}$} \\
\hline $\mathrm{N} 0+1$ & 1(Referent) & & & \\
\hline $\mathrm{N} 2+3$ & $3.108(1.814-5.325)$ & $<0.001$ & $2.249(1.243-4.070)$ & 0.071 \\
\hline \multicolumn{5}{|c|}{ TNM stage(AJCC) } \\
\hline $\mathrm{I}+\mathrm{II}$ & 1(Referent) & & & \\
\hline III+IV & $12.630(3.087-51.672)$ & $<0.001$ & $4.231(0.883-20.270)$ & 0.01 \\
\hline \multicolumn{5}{|l|}{ GGT } \\
\hline$<23$ & 1(Referent) & & & \\
\hline$\geq 23$ & $3.232(1.858-5.623)$ & $<0.001$ & $2.811(1.614-4.896)$ & 0.007 \\
\hline
\end{tabular}

GGT, Gamma-glutamyl transpeptidase; WHO, World Health Organization histological classification; TNM, tumor nodes metastasis-classification; AJCC, American Joint Committee on Cancer; HR, hazard ratio; 95\% CI, 95\% confidence interval.

to inflammation-related oxidative stress, but rather as the effect of specific inflammatory cytokines. Thus, GGT may influence the survival outcome of NPC patients by interacting with the GSH metabolism, oxidative stress and inflammation. However, the underlying mechanism still needs to be further explored in vivo and in vitro.

To the best of our knowledge, this was the first report that successfully confirmed a prognostic impact of pretreatment serum GGT in patients with NPC. This easily acquired enzyme in routine biochemical examination may complement TNM classification and allow patients to be further categorized based on the GGT, thus enable more individual treatments to be executed. Other serious diseases and medications which would affect the blood serum level of GGT were excluded. Hepatobiliary disease, concomitant malignant disease, congestive heart failure, anticonvulsants and alcohol abusewere excluded to minimize interferences. However, improper affirmation of prognostic markers is a paramount problem in current biomarker study. As GGT has been identified as a meaningful predictive biomarker for NPC patients, subsequent evaluation of its clinical benefit as a prognostic predictor in a large multi-center study needs to be carried out. Our original and objective research will offer a promising biomarker candidate for NPC and supplement the individualized treatment of NPC.

As a typical retrospective study, our study has some limitations such as lack of random assignments and its 

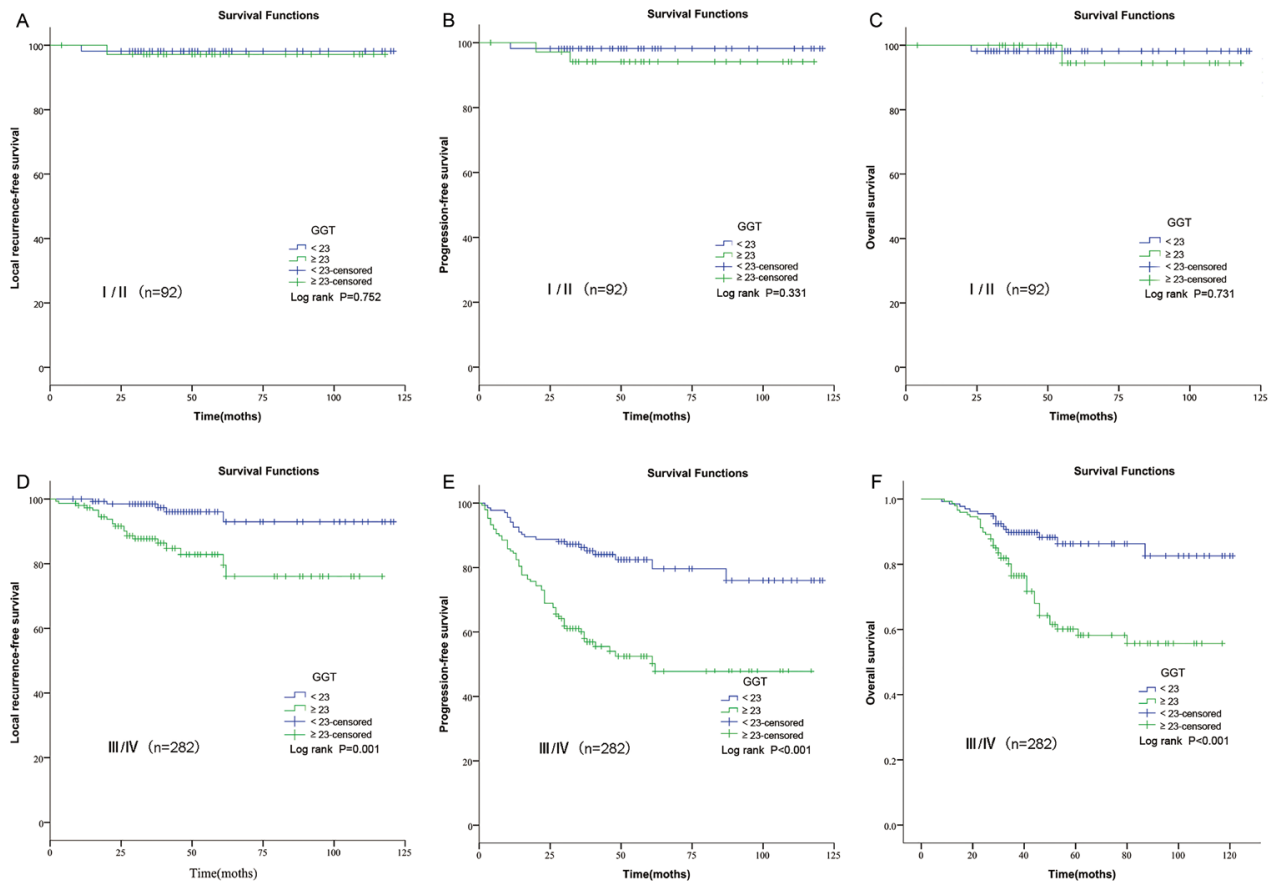

Figure 3: Kaplan-Meier curves for LRFS, PFS and OS rates according to pretreatment GGT in patients with different clinical stages. (A) LRFS stratified by GGT in patients with early-stage NPC. (B) PFS stratified by GGT in patients with early-stage NPC. (C) OS stratified by GGT in patients with early-stage NPC. (D) LRFS stratified by GGT in patients with advanced-stage NPC. (E) PFS stratified by GGT in patients with advanced-stage NPC. (F) OS stratified by GGT in patients with advanced-stage NPC.

GGT, gamma-glutamyl transpeptidase; LRFS, local relapse-free survival; PFS, progression-free survival; OS, overall survival; NPC, nasopharyngeal carcinoma.
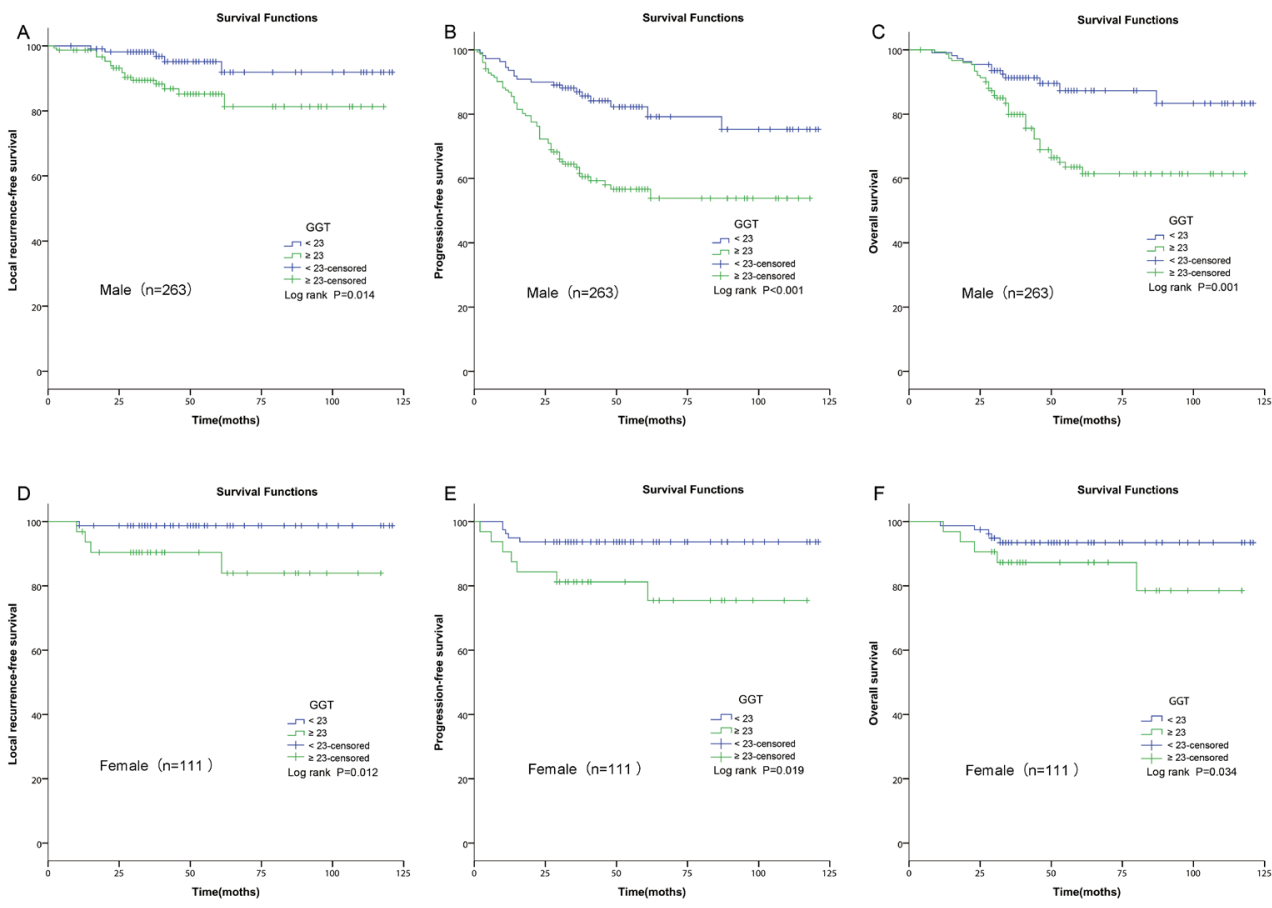

Figure 4: Kaplan-Meier curves for LRFS, PFS and OS rates according to pretreatment GGT in patients with different genders. (A) LRFS stratified by GGT in male patients with NPC. (B) PFS stratified by GGT in male patients with NPC. (C) OS stratified by GGT in male patients with NPC. (D) LRFS stratified by GGT in female patients with NPC. (E) PFS stratified by GGT in female patients with NPC. (F) OS stratified by GGT in female patients with NPC.

GGT, gamma-glutamyl transpeptidase; LRFS, local relapse-free survival; PFS, progression-free survival; OS, overall survival; NPC, nasopharyngeal carcinoma. 
single-institution. Besides, the number of included patients in our study was limited. Moreover, not all hematologic markers were adopted in our analysis because of our inability to obtain them, such as the LDH [5], serum alkaline phosphatase [38], albumin [45], Epstein-Barr virus [7], c-reactive protein [8] etc. Despite the potential weaknesses, our results are clinically meaningful and might be a useful hypothesis for future trials.

We concluded that GGT was associated with gender, $\mathrm{N}$-stage and TNM stage in patients with NPC. Pretreatment GGT was identified as a novel and independent prognostic biomarker for NPC patients. Future large randomized trials are warranted to confirm and update our results.

\section{MATERIALS AND METHODS}

\section{Patient population}

We collected data from 374 patients who were pathologically diagnosed with NPC and treated in the Cancer Center, Tongji Hospital between January 2005 and December 2010. This study was approved by our Ethics Committee. The inclusion criteria for patients in this study were as follows: (1) histological diagnosis with NPC; (2) having routine check up before radical treatment; (3) no radiotherapy or chemotherapy before collection of blood for GGT measurements; (4) no evidence of distant metastasis or secondary carcinoma at first diagnosis; (5) complete radical radiotherapy, with or without chemotherapy; and (6) absence of other serious diseases and medications which would affect the blood level of GGT (i.e., concomitant malignant disease, acute or chronic pancreatitis, acute or chronic hepatitis, liver cirrhosis, intra- or post-hepatic biliary obstruction, cholangitis, congestive heart failure NYHA III-IV, anticonvulsants, alcohol abuse, and so on).

\section{GGT measurement}

As a part of clinical routine blood chemistry analysis, serum GGT was measured within 1-3 days before therapy in the morning after an overnight fast. Serum GGT concentrations were analyzed with an enzyme kinetic assay (Modular Hitachi 7600 and Hitachi 7080, Hitachi High-Technologies Corporation Tokyo, Japan). All the serum levels of GGT were detected in the same instrument by using the same reagent methodology.

\section{Treatment}

All patients underwent a pretreatment baseline evaluation, including complete medical history, physical and neurological examinations, hematology and biochemistry profiles, MRI scan of the neck and nasopharynx, chest radiography, whole body bone scanning and abdominal sonography. Union for
International Cancer Control/American Joint Committee on Cancer (UICC/AJCC) 2002 staging system was used to classify patients. Treatment plans were determined according to standard protocols depending on tumor stages and general health. According to our institutional guidelines, patients with stage I to IIa disease generally only received radical radiotherapy, whereas patients with stage IIb to IV disease received CCT and/or NACT or ACT chemotherapy. All patients received radical radiotherapy using conventional or intensity-modulated radiotherapy. The following cumulative doses were delivered to each region: nasopharyngeal region, 68-70 Gy; involved cervical node, 60-66 Gy. In addition to radiotherapy, certain patients also received CCT, NACT and ACT. The regimens of NACT included DP (docetaxel $75 \mathrm{mg} / \mathrm{m}^{2} \mathrm{IV}$ on day 1 plus cisplatin $90 \mathrm{mg} / \mathrm{m}^{2} \mathrm{IV}$ on day 1 , repeat every 3 weeks) and PF (cisplatin $90 \mathrm{mg} / \mathrm{m}^{2} \mathrm{IV}$ on day 1 plus 5 -fluorouracil $750 \mathrm{mg} / \mathrm{m}^{2} / \mathrm{d}$ continuously IV on day $1-5$, repeat every 3 weeks). CCT was performed during the period of radiotherapy (cisplatin $30 \mathrm{mg} / \mathrm{m}^{2}$ on day 1 , repeat every week). For patients received ACT, the DP or PF regimens (the same as NACT) were repeated every 3 weeks for 2-4 cycles.

\section{Follow-up}

After treatment, patients were followed-up with routine checkups in our hospital every 3 months during the first 3 years after treatment, every 6 months for the next 2 years and subsequently every year. LRFS was defined as the time from diagnosis to the date of local recurrence or the date of death or when censored at the latest date. DMFS was defined as the time from diagnosis to the date of distant metastases or the date of death or when censored at the latest date. PFS was defined as the time from diagnosis to the date of local failure/distant metastasis or the date of death or when censored at the latest date. OS was defined as the time from diagnosis to the date of death or last follow-up visit if the patients were still alive.

\section{Statistical analysis}

ROC curve generated by MedCalc 9.6.2.0 (MedCalc Software, Mariakerke, Belgium) was used to determine the optimal cutoff value for GGT that yielded the highest combined sensitivity and specificity with respect to distinguishing 5-year survivors from non-survivors. According to the cutoff value of GGT, NPC patients were divided into high-risk group and low-risk group. Chisquare test was performed to evaluate the associations between the clinical-pathological variables and GGT. Kaplan-Meier method and log-rank test were adopted to calculate and compare the LRFS, DMFS, PFS and OS rates. Univariate and multivariate analyses were applied to determine independent factors that were significantly related to the prognosis. All statistical analyses were 
performed with SPSS19.0 (SPSS, Chicago, IL). A twosided p-value less than 0.05 was considered statistically significant.

\section{ACKNOWLEDGMENTS}

This study was supported by the National Natural Science Foundation of China $(81272491,81572960)$.

\section{CONFLICTS OF INTEREST}

We declare that we have no conflicts of interest.

\section{REFERENCES}

1. Li ZQ, Xia YF, Liu Q, Yi W, Liu XF, Han F, Luo W, Lu TX. Radiotherapy-related typing in 842 patients in canton with nasopharyngeal carcinoma. Int J Radiat Oncol Biol Phys. 2006; 66:1011-1016.

2. Lee AW, Ma BB, Ng WT, Chan AT. Management of nasopharyngeal carcinoma: current practice and future perspective. J Clin Oncol. 2015; 33:3356-3364.

3. Leung TW, Tung SY, Sze WK, Wong FC, Yuen KK, Lui CM, Lo SH, Ng TY. Treatment results of 1070 patients with nasopharyngeal carcinoma: an analysis of survival and failure patterns. Head Neck. 2005; 27:555-565.

4. Chen $\mathrm{W}, \mathrm{Hu} \mathrm{GH}$. Biomarkers for enhancing the radiosensitivity of nasopharyngeal carcinoma. Cancer Biol Med. 2015; 12:23-32.

5. Wan XB, Wei L, Li H, Dong M, Lin Q, Ma XK, Huang PY, Wen JY, Li X, Chen J, Ruan DY, Lin ZX, Chen ZH, et al. High pretreatment serum lactate dehydrogenase level correlates with disease relapse and predicts an inferior outcome in locally advanced nasopharyngeal carcinoma. Eur J Cancer. 2013; 49:2356-2364.

6. Sun W, Zhang L, Luo M, Hu G, Mei Q, Liu D, Long G, Hu G. Pretreatment hematologic markers as prognostic factors in patients with nasopharyngeal carcinoma: neutrophillymphocyte ratio and platelet-lymphocyte ratio. Head Neck. 2016; 38:E1332-E1340.

7. Xu J, Wan XB, Huang XF, Chan KC, Hong MH, Wang LH, Long ZJ, Liu Q, Yan M, Lo YM, Zeng YX, Liu Q. Serologic antienzyme rate of Epstein-Barr virus DNase-specific neutralizing antibody segregates TNM classification in nasopharyngeal carcinoma. J Clin Oncol. 2010; 28:5202-5209.

8. Xia WX, Zhang HB, Shi JL, Lu X, Wang L, Ye YF, Cao KJ, Qian CN, Guo X, Xiang YQ. A prognostic model predicts the risk of distant metastasis and death for patients with nasopharyngeal carcinoma based on pre-treatment serum C-reactive protein and N-classification. Eur J Cancer. 2013; 49:2152-2160.
9. Orlowski M, Meister A. The gamma-glutamyl cycle: a possible transport system for amino acids. Proc Natl Acad Sci U S A. 1970; 67:1248-1255.

10. Whitfield JB. Gamma glutamyl transferase. Crit Rev Clin Lab Sci. 2001; 38:263-355.

11. Hanigan MH, Gallagher BC, Townsend DM, Gabarra V. Gamma-glutamyl transpeptidase accelerates tumor growth and increases the resistance of tumors to cisplatin in vivo. Carcinogenesis. 1999; 20:553-559.

12. Franzini M, Corti A, Lorenzini E, Paolicchi A, Pompella A, De Cesare M, Perego P, Gatti L, Leone R, Apostoli $\mathrm{P}$, Zunino F. Modulation of cell growth and cisplatin sensitivity by membrane gamma-glutamyltransferase in melanoma cells. Eur J Cancer. 2006; 42:2623-2630.

13. Pompella A, De Tata V, Paolicchi A, Zunino F. Expression of gamma-glutamyltransferase in cancer cells and its significance in drug resistance. Biochem Pharmacol. 2006; 71:231-238.

14. Hofbauer SL, Stangl KI, de Martino M, Lucca I, Haitel A, Shariat SF, Klatte T. Pretherapeutic gammaglutamyltransferase is an independent prognostic factor for patients with renal cell carcinoma. Br J Cancer. 2014; 111:1526-1531.

15. Yang $\mathrm{F}$, Zhang $\mathrm{S}$, Yang $\mathrm{H}$, Luo $\mathrm{K}$, Wen $\mathrm{J}, \mathrm{Hu} \mathrm{Y}, \mathrm{Hu}$ $\mathrm{R}$, Huang Q, Chen J, Fu J. Prognostic significance of gamma-glutamyltransferase in patients with resectable esophageal squamous cell carcinoma. Dis Esophagus. 2015; 28:496-504.

16. Strasak AM, Goebel G, Concin H, Pfeiffer RM, Brant LJ, Nagel G, Oberaigner W, Concin N, Diem G, Ruttmann E, Gruber-Moesenbacher U, Offner F, Pompella A, et al. Prospective study of the association of serum gammaglutamyltransferase with cervical intraepithelial neoplasia III and invasive cervical cancer. Cancer Res. 2010; 70:3586-3593.

17. He WZ, Guo GF, Yin CX, Jiang C, Wang F, Qiu HJ, Chen XX, Rong R, Zhang B, Xia L. Gamma-glutamyl transpeptidase level is a novel adverse prognostic indicator in human metastatic colorectal cancer. Colorectal Dis. 2013; 15:e443-e452.

18. Staudigl C, Concin N, Grimm C, Pfeiler G, Nehoda R, Singer $\mathrm{CF}$, Polterauer S. Prognostic relevance of pretherapeutic gamma-glutamyltransferase in patients with primary metastatic breast cancer. PLoS One. 2015; 10:e0125317.

19. Polterauer S, Hofstetter G, Grimm C, Rahhal J, MailathPokorny M, Kohl M, Concin N, Tempfer C, Marth C, Reinthaller A. Relevance of gamma-glutamyltransferase--a marker for apoptotic balance--in predicting tumor stage and prognosis in cervical cancer. Gynecol Oncol. 2011; 122:590-594.

20. Grimm C, Hofstetter G, Aust S, Mutz-Dehbalaie I, Bruch M, Heinze G, Rahhal-Schupp J, Reinthaller A, Concin N, Polterauer S. Association of gamma-glutamyltransferase 
with severity of disease at diagnosis and prognosis of ovarian cancer. Br J Cancer. 2013; 109:610-614.

21. Schiele F, Guilmin AM, Detienne H, Siest G. Gammaglutamyltransferase activity in plasma: statistical distributions, individual variations, and reference intervals. Clin Chem. 1977; 23:1023-1028.

22. Lee AW, Lin JC, Ng WT. Current management of nasopharyngeal cancer. Semin Radiat Oncol. 2012; 22:233-244.

23. Baujat B, Audry H, Bourhis J, Chan AT, Onat H, Chua DT, Kwong DL, Al-Sarraf M, Chi KH, Hareyama M, Leung SF, Thephamongkhol K, Pignon JP. Chemotherapy in locally advanced nasopharyngeal carcinoma: an individual patient data meta-analysis of eight randomized trials and 1753 patients. Int J Radiat Oncol Biol Phys. 2006; 64:47-56.

24. Tsang J, Lee VH, Kwong DL. Novel therapy for nasopharyngeal carcinoma - where are we. Oral Oncol. 2014; 50:798-801.

25. Kwong D, Sham J, Choy D. The effect of loco-regional control on distant metastatic dissemination in carcinoma of the nasopharynx: an analysis of 1301 patients. Int J Radiat Oncol Biol Phys. 1994; 30:1029-1036.

26. Wolden SL, Chen WC, Pfister DG, Kraus DH, Berry SL, Zelefsky MJ. Intensity-modulated radiation therapy (IMRT) for nasopharynx cancer: update of the Memorial SloanKettering experience. Int J Radiat Oncol Biol Phys. 2006; 64:57-62.

27. Jin Y, Cai XY, Cai YC, Cao Y, Xia Q, Tan YT, Jiang WQ, Shi YX. To build a prognostic score model containing indispensible tumour markers for metastatic nasopharyngeal carcinoma in an epidemic area. Eur J Cancer. 2012; 48:882-888.

28. Lan M, Chen C, Huang Y, Mao M, Han F, Liao J, Deng M, Duan Z, Zheng L, Wu S, Lu T, Jian Y. Elevated plasma fibrinogen level shows superior prognostic value than Epstein-Barr virus DNA load for stage IVA/B nasopharyngeal carcinoma patients in the intensitymodulated radiotherapy era. Oncotarget. 2016; 7:4624246252. doi: 10.18632/oncotarget.10083.

29. Liu YY, Lin SJ, Chen YY, Liu LN, Bao LB, Tang LQ, Ou JS, Liu ZG, Chen XZ, Xu Y, Ma J, Chan AT, Chen M, et al. Highdensity lipoprotein cholesterol as a predictor of poor survival in patients with nasopharyngeal carcinoma. Oncotarget. 2016; 7:42978-42987. doi: 10.18632/oncotarget.7160.

30. Strasak AM, Pfeiffer RM, Klenk J, Hilbe W, Oberaigner W, Gregory M, Concin H, Diem G, Pfeiffer KP, Ruttmann E, Ulmer H. Prospective study of the association of gammaglutamyltransferase with cancer incidence in women. Int $\mathrm{J}$ Cancer. 2008; 123:1902-1906.

31. Strasak AM, Rapp K, Brant LJ, Hilbe W, Gregory M, Oberaigner W, Ruttmann E, Concin H, Diem G, Pfeiffer $\mathrm{KP}$, Ulmer H. Association of gamma-glutamyltransferase and risk of cancer incidence in men: a prospective study. Cancer Res. 2008; 68:3970-3977.
32. Van Hemelrijck M, Jassem W, Walldius G, Fentiman IS, Hammar N, Lambe M, Garmo H, Jungner I, Holmberg L. Gamma-glutamyltransferase and risk of cancer in a cohort of 545,460 persons - the Swedish AMORIS study. Eur J Cancer. 2011; 47:2033-2041.

33. Ruhl CE, Everhart JE. Elevated serum alanine aminotransferase and gamma-glutamyltransferase and mortality in the United States population. Gastroenterology. 2009; 136:477-485.e411.

34. Hochwald SN, Rose DM, Brennan MF, Burt ME. Elevation of glutathione and related enzyme activities in high-grade and metastatic extremity soft tissue sarcoma. Ann Surg Oncol. 1997; 4:303-309.

35. Godwin AK, Meister A, O'Dwyer PJ, Huang CS, Hamilton TC, Anderson ME. High resistance to cisplatin in human ovarian cancer cell lines is associated with marked increase of glutathione synthesis. Proc Natl Acad Sci U S A. 1992; 89:3070-3074.

36. Mares V, Lisa V, Malik R, Kozakova H, Sedo A. Cisplatin induced gamma-glutamyltransferase up-regulation, hypertrophy and differentiation in astrocytic glioma cells in culture. Histol Histopathol. 2003; 18:687-693.

37. Lewis AD, Hayes JD, Wolf CR. Glutathione and glutathione-dependent enzymes in ovarian adenocarcinoma cell lines derived from a patient before and after the onset of drug resistance: intrinsic differences and cell cycle effects. Carcinogenesis. 1988; 9:1283-1287.

38. Li G, Gao J, Tao YL, Xu BQ, Tu ZW, Liu ZG, Zeng MS, Xia YF. Increased pretreatment levels of serum LDH and ALP as poor prognostic factors for nasopharyngeal carcinoma. Chin J Cancer. 2012; 31:197-206.

39. Hanigan MH, Ricketts WA. Extracellular glutathione is a source of cysteine for cells that express gamma-glutamyl transpeptidase. Biochemistry. 1993; 32:6302-6306.

40. Hanigan MH. Gamma-glutamyl transpeptidase: redox regulation and drug resistance. Adv Cancer Res. 2014; 122:103-141.

41. Koenig G, Seneff S. Gamma-glutamyltransferase: a predictive biomarker of cellular antioxidant inadequacy and disease risk. Dis markers. 2015; 2015:818570.

42. Toyokuni S, Okamoto K, Yodoi J, Hiai H. Persistent oxidative stress in cancer. FEBS Lett. 1995; 358:1-3.

43. Daubeuf S, Accaoui MJ, Pettersen I, Huseby NE, Visvikis A, Galteau MM. Differential regulation of gammaglutamyltransferase mRNAs in four human tumour cell lines. Biochim Biophys Acta. 2001; 1568:67-73.

44. Bouman L, Sanceau J, Rouillard D, Bauvois B. gammaGlutamyl transpeptidase expression in Ewing's sarcoma cells: up-regulation by interferons. Biochem J. 2002; 364:719-724.

45. Liu X, Meng QH, Ye Y, Hildebrandt MA, Gu J, Wu X. Prognostic significance of pretreatment serum levels of albumin, LDH and total bilirubin in patients with nonmetastatic breast cancer. Carcinogenesis. 2015; 36:243-248. 